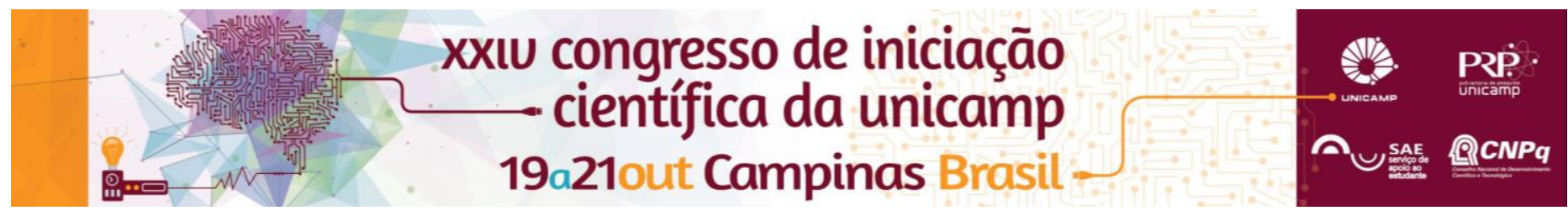

\title{
Difusão do conhecimento em saúde relacionado à obesidade e ao diabetes mellitus tipo 2: Intervenções voltadas a promoção de saúde e adesão ao tratamento.
}

\author{
Ana Maria Tordin*, Bianca B. M. Fonseca*, Bruno O. Silva*, Luana Pereira*, Mariana F. Bombini, Guilherme A. S. \\ Nogueira, Vanessa C. Bóbbo, Eliana P. de Araújo.
}

\section{Resumo}

A obesidade predispõe o indivíduo a uma série de doenças crônicas não transmissíveis, como o diabetes mellitus tipo 2 (DM2) e doenças cardiovasculares. As atividades de promoção à saúde, prevenção e tratamento são voltadas a adoção de padrões de vida saudáveis, como alimentação balanceada e prática de atividade física. A dificuldade de adesão aos padrões recomendados leva a reflexão de práticas educativas que favoreçam a sensibilização do indivíduo e da comunidade quanto à necessidade destas mudanças em suas rotinas. O objetivo deste trabalho foi desenvolver estratégias de difusão do conhecimento em saúde para jovens, adultos e idosos, a respeito de obesidade e DM2. Após cumprimento do cronograma de estudos da equipe, o trabalho foi voltado para o desenvolvimento de uma peça teatral e de um aplicativo de celular, ambos relacionados ao tema obesidade e diabetes. As estratégias de difusão do conhecimento em saúde voltadas para obesidade e diabetes geram impacto positivo para a população, contribuindo com a prevenção e melhorando a adesão ao tratamento destes problemas de saúde.

\section{Palavras-chave: \\ Educação, Obesidade, Diabetes.}

\section{Introdução}

A obesidade é o resultado do desequilíbrio entre ingestão calórica e gasto energético ${ }^{1}$. Ela está associada a maior risco de morte prematura, principalmente por predispôr o indivíduo a doenças crônicas não transmissíveis, como o DM2 ${ }^{2}$. Até o momento medidas terapêuticas não invasivas eficazes para o tratamento de indivíduos obesos residem na perda de peso por meio de mudanças no estilo de vida, como 0 comportamento alimentar e prática de atividade física ${ }^{3}$. A eficiência das terapias propostas e das intervenções voltadas a promoção de saúde e prevenção, dependem do envolvimento e adesão do indivíduo. Faz-se necessário o desenvolvimento de intervenções que tenham sua prática voltada à independência e ao empoderamento ${ }^{4}$.

Nossa hipótese baseia-se na efetividade da promoção da saúde, prevenção e adesão ao tratamento estar relacionada a adoção de práticas educativas que levem a busca pelo autocuidado, autopercepção e adoção de cuidados voltados à prevenção e ao tratamento de obesidade e DM2. Nosso objetivo foi desenvolver estratégias de difusão do conhecimento em saúde para jovens, adultos e idosos, a respeito de obesidade e DM2.

\section{Resultados e Discussão}

Primeiramente, a equipe (alunos, monitores, docente) estudou conteúdos relacionados à obesidade e ao diabetes, relacionando a conhecimentos prévios e elementos da realidade vivenciada por cada membro. Realizou-se visitas ao Laboratório de Sinalização Celular e ao Ambulatório Geral de Adultos do Hospital de Clínicas da Unicamp. Em seguida, a equipe trabalhou em estratégias de difusão do conhecimento e desenvolvimento de materiais educativos acerca do tema.

As propostas elencadas foram o desenvolvimento de uma peça teatral com os temas obesidade e diabetes, entitulada "Fat wars: as aventuras de uma banana", bem como o desenvolvimento de um aplicativo de celular (App).

A peça teatral foi desenvolvida pela equipe com proposta lúdica e divertida, e debate sobre o caminho percorrido pelos alimentos no sistema digestivo, a importância da alimentação saudável utilizando a pirâmide alimentar e a relação entre sistema nervoso, obesidade e diabetes. A peça foi exposta na Semana do Diabetes da Unicamp em 2015, no encerramento do Ciência e Arte nas Férias da Unicamp em 2016, e foi registrada em vídeo para reprodução em espaços públicos.

O App consiste num jogo baseado nos personagens e elementos da peça teatral. As fases e desafios do jogo são permeadas por informações acerca de alimentação, curiosidades, e informações sobre obesidade e diabetes, relevantes para sua prevenção e tratamento. $O$ aplicativo de celular foi desenvolvido para a plataforma Android $\AA$, utilizando o software MIT App Inventor 2.

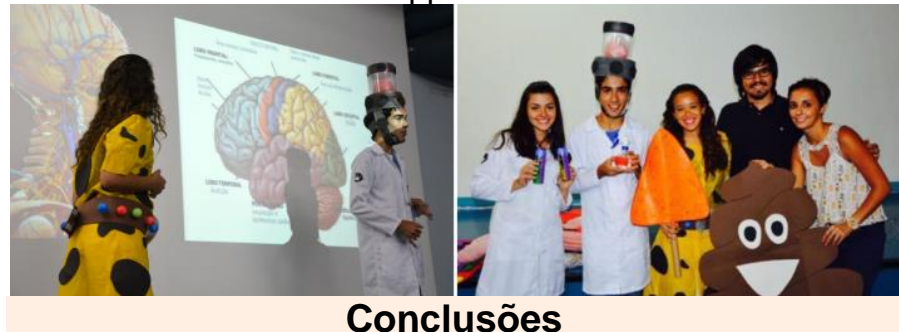

As estratégias de difusão do conhecimento em saúde voltadas para obesidade e diabetes são necessárias devido ao tratamento ser voltado para mudanças de comportamento. Assim, geram impacto positivo para a população, contribuindo com a prevenção e melhorando a adesão ao tratamento da obesidade e diabetes.

\section{Agradecimentos}

\section{Ao CEPID-FAPESP OCRC e à FAEPEX.}

\footnotetext{
${ }^{1}$ Flier JS. Obesity wars: molecular progress confronts an expanding epidemic. Cell. 2004; 116(2): 337-350

2 Velloso LA. O Controle Hipotalâmico da Fome e da Termogênese Implicações no Desenvolvimento da Obesidade. Rev Bras Endocrinol Metab. 2006; 50(2): 165-176

${ }^{3}$ Diabetes Prevention Program. The Diabetes Prevention Program design and methods for a clinical trial in the prevention of type 2 diabetes. Diabetes Care. 1999; 22: 623-634.

5 Silveira LMC, Ribeiro VMB. Grupo de adesão ao tratamento: espaço de "ensinagem" para profissionais de saúde e pacientes. Interface - Comunic, Saúde, Educ, v.9, n.16, p.91-104, set.2004/fev.2005
} 